\title{
Formação docente: um processo carregado de intencionalidade
}

\author{
Formación docente: un procedimiento cargado de intencionalidades
}

Teacher training: a process charged with intentionalities

\author{
Karine Dias Maximila ${ }^{1}$ \\ Silvana Maria Gritti
}

\begin{abstract}
Resumo
O artigo versa acerca da Formação de Professores no Brasil, inserida num contexto carregado de intencionalidades, que cada vez mais desvaloriza a docência e a afasta da autonomia. Faz uma referência ao contexto histórico da formação docente para compreendermos algumas questões, que ainda se destacam dentro das escolas e elucidam a centralidade nas propostas educativas que evidenciam uma educação seletiva, competitiva e excludente. $\mathrm{O}$ manuscrito tem como referência o pensamento Freiriano, e objetiva promover a reflexão sobre a necessidade de um processo formativo que ponha em xeque as ações e concepções docentes bancárias, que ainda no século XXI permeiam fortemente as ações educativas. Apresenta experiências de caráter formativo, vivenciadas durante reuniões pedagógicas de uma escola municipal de Santa Vitória do Palmar-RS, que serviram de lócus para o desenvolvimento de uma pesquisa-ação de abordagem qualitativa, e propõe que se pense na formação continuada de professores a partir das problemáticas e necessidades que se apresentam efetivamente em seu trabalho.
\end{abstract}

Palavras-chave: Formação de professores; Autonomia; Pesquisa; Reflexão; Participação.

\section{Resumen}

El artículo versa sobre la formación de profesores en Brasil, inserta en un contexto cargado de intencionalidades, que cada vez más desvaloriza la docencia y la aleja de la autonomía. Hace una referencia al contexto histórico de la formación docente para comprender algunas cuestiones, que aún se destacan dentro de las escuelas y elucidan la centralidad en las propuestas educativas que evidencian una educación selectiva, competitiva y excluyente. El manuscrito tiene como referencia el pensamiento Freiriano, y tiene como objetivo promover la reflexión sobre la necesidad de un proceso formativo que ponga en jaque las acciones y concepciones docentes bancarias, que aún en el siglo XXI permean fuertemente las acciones educativas. En el caso de los alumnos de la escuela secundaria de Santa Vitória del palmar-RS, que sirvieron de locus para el desarrollo de una investigación-acción de abordaje cualitativo, propone que se piense en la formación continuada de profesores a partir de las reuniones pedagógicas de una escuela municipal de Santa Victoria del Palmar-RS de las problemáticas y necesidades que se presentan efectivamente en su trabajo.

Palabras clave: Formación de profesores; Autonomía; La investigación; La reflexión; Participación.

\begin{abstract}
The article deals with Teacher Training in Brazil, inserted in a context loaded with intentionalities, which increasingly devalues teaching and distances it from autonomy. It makes reference to the historical context of teacher education to understand some issues, which still stand out within the schools and elucidate the centrality

\footnotetext{
${ }^{1}$ Mestranda em Educação - Universidade Federal do Pampa (UNIPAMPA). Jaguarão/RS (Brasil). E-mail: kmaximila@hotmail.com

${ }^{2}$ Doutora pela Universidade Federal do Rio Grande do Sul (UFRGS). Professora da Universidade Federal do Pampa (UNIPAMPA). Jaguarão/RS (Brasil). E-mail: silvanagritti@gmail.com
} 
in the educational proposals that evidence a selective, competitive and exclusive education. The manuscript is based on Freiriano thought, and aims to promote reflection on the need for a formative process that puts in check the actions and conceptions of banking teachers, who still in the 21 st century strongly permeate educational actions. It presents formative experiences, lived during pedagogical meetings of a municipal school of Santa Vitória do Palmar-RS, that served as locus for the development of an action research of qualitative approach, and proposes that one thinks about the continued formation of teachers from the problems and needs that are present in their work.

Palavras-chave: Teacher training; Autonomy; Search; Reflection; Participation.

\section{Introdução}

O presente texto é parte da pesquisa de Mestrado Profissional do Programa de PósGraduação em Educação (PPGEdu), da Universidade Federal do Pampa (UNIPAMPA) da cidade de Jaguarão - RS. Estrutura-se em pesquisa bibliográfica a partir de reflexões teóricas envolvendo a formação docente, a partir da compreensão de sua constituição histórica e de sua potencialidade em contribuir para transformar a realidade problemática que está posta na educação brasileira.

A pesquisa que vem sendo desenvolvida sob o título "Reuniões Pedagógicas: Espaço público de produção de conhecimento", investiga a formação de professores, para que por meio desta, nos possibilite compreender a constituição docente e potencializar a reunião pedagógica como espaço coletivo de construção de conhecimentos a partir do chão da escola. Os conflitos que se apresentam na relação professor aluno, durante a dinâmica do trabalho docente e os encaminhamentos dados a essas problemáticas, reacendem a necessidade de um espaço formativo que de voz aos professores para que estes busquem apropriar-se do seu fazer pedagógico, tendo autonomia e conhecimento para gerenciar as suas demandas.

O contexto histórico da formação docente compreende algumas questões destacadas por Celani (1988), Nóvoa (1995), Imbernón (2010) e Marcelo (2013), que afirmam a concretude, ainda nos dias atuais, de algumas atitudes e posturas dentro das escolas capazes de mostrarem a centralidade nas propostas educativas que evidenciam uma educação bancária e excludente. Desta forma, este artigo tem como objetivo refletir sobre a necessidade de um processo formativo que modifique as ações docentes, visto que ainda no século XXI a educação bancária permeia as ações educativas. Freire ressalta que na educação bancária:

Em lugar de comunicar-se, o educador faz "comunicados" e depósitos que os educandos, meras incidências, recebem pacientemente, memorizam e repetem. Eis aí a concepção "bancária" da educação, em que a única margem de ação que se oferece aos educandos é a de receberem os depósitos, guardá-los e arquivá-los. Margem para serem colecionadores ou fichadores das coisas que arquivam. No fundo, porém, os grandes arquivados são os homens, nesta (na melhor das hipóteses) equivocada 
concepção "bancária" da educação. Arquivados, porque, fora da busca, fora da práxis, os homens não podem ser. Educador e educandos se arquivam na medida em que, nesta destorcida visão da educação, não há criatividade, não há transformação, não há saber (FREIRE, 1987, p. 33).

Neste sentido, a docência está condicionada às práticas que perpetuam sistemas dominantes de educação, que reproduzem na sala de aula o autoritarismo no embate com os alunos e o excessivo rigor e apego a regras de controle. Percebendo que somos produto de um contexto histórico formativo, Freire cita que:

Não há possibilidade de pensarmos o amanhã, mais próximo ou mais remoto, sem que nos achemos em processo permanente de "emersão" do hoje, "molhados" do tempo que vivemos, tocados por seus desafios, instigados por seus problemas [...] (2000, p. 117).

O professor, em sua formação acadêmica, não desconstrói valores que se instituíram em sua vida enquanto aluno e sujeito de uma sociedade seletiva. Ele precisa fazer uma análise de sua constituição profissional para que a partir desta possa compreender-se como sujeito inacabado possível de transformação e de transcender suas concepções em relação ao trabalho docente.

$\mathrm{Na}$ verdade, eles terminam sua formação sem terem sido abalados em suas crenças, e são essas crenças que vão se reatualizar no momento de aprenderem a profissão na prática, crenças essas que serão habitualmente reforçadas pela socialização na função de professores e pelo grupo de trabalho nas escolas, a começar pelos pares, os professores experientes (TARDIF, 2000, p. 20).

O autor faz refletir sobre as relações de ensino que ocorrem também dentro da sala de aula, entre professor e alunos, as quais se apresentam na maioria das vezes conflituosas em detrimento de uma relação autoritária ou de um discurso conformista acerca da incapacidade de superar essa condição de trabalho, que gera um sentimento de desvalorização e desgosto pela profissão. Por vezes, a relação que ocorre na sala de aula, transparece o condicionamento técnico do profissional da educação e desconsidera a competência de mediação do ensino e aprendizagem, distanciando o professor cada vez mais de seu instrumento de trabalho.

Contrapondo-se a essa corrente de desvalorização profissional do professor e as concepções que o consideram como simples técnico reprodutor de conhecimentos e ou monitor de programas pré-elaborados, entendo que na sociedade contemporânea cada vez mais se torna necessário seu trabalho enquanto mediação aos processos constitutivos de cidadania dos alunos, para que consiga a superação do fracasso escolar e das desigualdades escolares. $\mathrm{O}$ que parece, impõe a necessidade de repensar a formação de professores (PIMENTA, 1999, p. 15). 
Esta necessidade se deve a formação de características tradicionais e conservadoras que os profissionais da educação obtiveram, que contempla um modelo societário excludente e alienador, e reproduz uma prática pedagógica que ignora a relação entre teoria e prática, e desta forma contribui para a perpetuação do afastamento docente da autonomia. Conforme Carvalho (2005, p. 20) a "mudança só se efetivará à medida que o professor ampliar sua consciência sobre a própria prática, visto que 'pensar a prática' é o ponto de partida para alterá-la. O alargamento da consciência, por sua vez, se dá pela reflexão que o professor realiza de sua ação".

\title{
2. O percurso histórico da formação docente e suas intencionalidades
}

O percurso histórico da formação docente, não tem apresentado o interesse e a preocupação em estabelecer situações que possibilitem aos professores terem autonomia para elaborarem no espaço pedagógico relações de equilíbrio entre o conhecimento teórico e seu fazer docente, numa ação consciente que transforme a realidade, e que os aproprie da realidade em que estão inseridos para transformá-la, com base nisso Freire (2011, p. 61) alerta que "Por isso, desde já, salienta-se a necessidade de uma permanente atitude crítica, único modo pelo qual o homem realizará sua vocação natural de integrar-se, superando a atitude do simples ajustamento ou acomodação [...]”. Deste modo, fica aparente a relevância de a partir da compreensão da constituição da docência ter-se um olhar atento para as políticas que definem estratégias e norteiam a formação docente, visto que os professores precisam estarem inseridos e protagonizarem os fundamentos que estabelecem os princípios da formação dos profissionais da educação. Freire (2005) destaca que:

\begin{abstract}
A educação libertadora, problematizadora, já não pode ser o ato de depositar, ou de narrar, ou de transferir, ou de transmitir "conhecimentos" e valores aos educandos, meros pacientes, à maneira da educação "bancária", mas um ato cognoscente... O antagonismo entre as duas concepções, uma, a "bancária" [grifos do autor], que serve à dominação; outra, a problematizadora, que serve à libertação, toma corpo exatamente aí. Enquanto a primeira, necessariamente, mantém a contradição educador-educando, a segunda realiza a superação (p. 78).
\end{abstract}

Não havendo uma análise crítica que possibilite a compreensão do papel e função da profissão docente, não ocorrerá uma formação coerente com a atual necessidade de educação no país, é imprescindível que se forme profissionais capacitados à prática da liberdade. A docência necessita compreender-se como elemento que contribui para a caracterização de uma sociedade, assim assumindo seu papel sem condiciona-se as intencionalidades 
governamentais, passando a produzir conhecimento a partir do fazer pedagógico como instrumento de validação para a autonomia e valorização da profissão.

As Diretrizes Curriculares Nacionais para a Formação de Professores da Educação Básica, instituídas em 2002, orientaram para o princípio da ação-reflexão-ação, em seu artigo $12^{\circ}$, cita que "a prática deverá estar presente desde o início do curso e permear toda a formação do professor". Uma bela tentativa para que os docentes se apropriassem do pensar, decidir e agir, porém, enquanto as políticas públicas em relação à educação estiverem minadas de intencionalidades de quem as produz (políticos, governantes), não se terá sucesso e se continuará tendo a reprodução bancária dentro das escolas.

\begin{abstract}
Os docentes não devem ser, simplesmente, uma parte num conflito entre pretensões e finalidades educativas. Parte de sua profissão deve consistir em mediar estes conflitos de maneira que se possa entender o sentido e o valor de cada posição e encontrar a forma em que a escola possa realizar sua missão, sem limitar-se a ser o estopim das contradições, nem a seguir irrefletidamente as diretrizes, ordens, correntes ou pressões do exterior (CONTRERAS, 2002, p. 80).
\end{abstract}

Ao passo que os professores continuarem a ser excluídos das tomadas de decisões que estabelecem os rumos da educação, desconsiderando a propriedade que estes possuem acerca da compreensão das dificuldades e necessidades que caracterizam a educação brasileira, não haverá um profissional fruto de uma formação que seja capaz de realizar uma transformação social, por meio da construção do conhecimento, porque lhes faltará autonomia. Justamente como refere Contreras (2002, p. 225) “A participação dos professores no debate público sobre a educação, a partir de sua própria especificidade como docentes, supõe estabelecer conexões entre sua experiência interna do ensino e seu significado e repercussões sociais". Deste modo, a intenção das diretrizes instituídas em 2002, ao privilegiar a prática durante a formação, não promoveu significativo avanço na formação de professores.

Outra medida, que define bem as intencionalidades que promovem mudanças pensando a formação de professores em quantidade e não com qualidade e competência, foi a implementação do ensino a distância, para suprir a necessidade apontada pela LDB 9.394/96, de formar em ensino superior todos os docentes antes do término da década estabelecida (2007). Assim, o Decreto n. 2.494, de 10 de Fevereiro de 1998, regulamentando o art.80 da Lei n. 9394, de 20 de dezembro de 1996, define:

Art 1 - Educação a distância é uma forma de ensino que possibilita a autoaprendizagem, apresentados a mediação de recursos didáticos sistematicamente organizados, apresentados em diferentes suportes de 
informação, utilizados isoladamente ou combinados, e veiculados pelos diversos meios de comunicação.

Parágrafo único. Os cursos ministrados sob forma de educação a distância serão organizados em regime especial, com flexibilidade de requisitos para admissão, horário e duração, sem prejuízo, quando for o caso, dos objetivos e das diretrizes curriculares fixadas nacionalmente.

Art 2- Os cursos a distância que conferem certificado ou diploma de conclusão do ensino fundamental para jovens e adultos, do ensino médio, da educação profissional, e de graduação, serão oferecidos por instituições públicas ou privados especificamente credenciados para esse fim, nos termos deste Decreto e conforme exigências a serem estabelecidas em ato próprio, expedido pelo Ministro de Estado da Educação e do Desporto.

A implementação dessa modalidade de ensino para a formação de professores fragilizou ainda mais a docência, de modo que se tornou um atrativo aos grandes investidores da educação. A graduação passou a ser comercializada em todo o país, produzindo em larga escala profissionais que passariam a atuar na educação brasileira, já tão problemática. Muito característico do modelo de produção da sociedade em que vivemos, a educação a distância, apresenta-se como a solução de um problema de forma imediata, muito preocupada com o resultado final, a titulação e inserção no mercado de trabalho, sem atentar-se ao percurso e a forma que se dará a constituição dessa formação, contribuindo para mais um fracasso do avanço do ensino no Brasil.

A formação a distância priva os professores da experiência acadêmica, das relações que acontecem nesse espaço de interação, provocando um distanciamento do maior princípio que o processo de constituir um docente deve buscar, a autonomia.

\footnotetext{
As pessoas precisam de relações diretas, vis-à-vis, pois a presença do outro é o balizador principal do agir humano. A autonomia, por exemplo, tida como a atitude ou o modo de ser específico da sociedade emancipada, moderna e democrática, é, na verdade, a expressão de uma relação entre pessoas, uma relação de igualdade e de respeito que mobiliza a dimensão individual e livre de cada um (GIOLO, 2008, p. 1228).
}

Sem a possibilidade de ter sua criticidade e autonomia despertada em seu processo de formação, e com a dura realidade atual de cumprirem uma jornada de trabalho exaustiva, o professor tem desenvolvido seu trabalho de forma a reproduzir técnicas e modelos pedagógicos que não tem sustentado a emancipação dos sujeitos que pretende formar.

De alguma forma, é apenas quando o docente está na sala de aula, que lhe ocorre a necessidade de refletir sobre aspectos que lhe dificultam executar o que a academia propôs, em vista disto, ou este se frustra e busca num discurso simplista justificar o fracasso e impotência perante a realidade que se apresenta, ou se aproxima de uma quebra de paradigma 
que rompe com a alienação e revela a importância da aproximação com a pesquisa em função da melhoria das condições de trabalho, modificando suas concepções enquanto educador.

A complexidade da prática pedagógica evoca pesquisa e formação continuada, que estabeleçam mecanismos para que o professor supere suas crenças, reavalie seus valores e atitudes, reformulando-se para atender os desafios da atualidade. A partir destas questões surge à necessidade de que sua prática possa ser pensada por si, tornando-se agente ativo e reflexivo responsável por sua constituição profissional.

A formação deve contribuir para a mudança educacional e para a definição da profissão docente. Neste sentido, o espaço pertinente da formação contínua já não é o professor isolado, mas sim o professor inserido num corpo profissional e numa organização escolar (NOVOA, 2002, p. 38).

A pouco tempo, o governo lançou mão de mais um artifício pertinente à formação docente, disponibilizou por meio de uma plataforma chamada Freire, cursos de formação inicial e continuada. De forma geral, demonstra a inquietação com a promoção de estudos para os profissionais da educação. A Plataforma Freire é um investimento do projeto Plano Nacional de formação de Professores da Educação Básica MEC/2009 - Ministério de Educação e Cultura, a qual tem realizado o cadastramento do currículo de todos os professores da rede pública do país, com o objetivo de qualificar o ensino.

Mais uma vez apresenta-se a urgência de se atentar para a intencionalidade desse projeto, que muito se parece com controle e qualificação de mão de obra, sem diferença alguma das políticas públicas que a antecederam.

[...] não podemos deixar de considerar os efeitos e as consequências das inúmeras legislações, que ora mostram possibilidades para a ação dos educadores, ora rompem com essas mesmas possibilidades, e acabam por fortalecer uma política de aligeiramento, tanto na formação inicial, quanto nas ações de formação continuada (ABDALLA, 2012, p. 30).

A formação de professores busca uma política pública que considere a experiência como fator de referência para se pensar a prática no espaço da escola, e avançar no sentido da autonomia como "um direito trabalhista como uma necessidade educativa" (CONTRERAS, 2002, p. 195). Nessa relação de autonomia o docente terá consciência sobre o trabalho que realiza, expressando valores, pretensões e compreendendo suas finalidades.

Considerando as características históricas da formação de professores no Brasil, podemos compreender o descontínuo e desarticulado processo de instituição de Leis, Diretrizes e Decretos que articularam e estabeleceram fatores determinantes à realidade que se 
apresenta atualmente na educação brasileira. Também percebemos o conjunto de intencionalidades inerentes a uma sociedade capitalista, que promulgaram uma insuficiência no ensino, mesmo que contraditoriamente, a preocupação tenha sido com o melhoramento do nível do mesmo.

É na autonomia dos professores que reside a esperança de melhores condições de trabalho, de valorização profissional e renovação da atuação, como sustenta Contreras (2002, p. 185):

Enquanto emancipação, a autonomia suporia um processo contínuo de descobertas e de transformação das diferenças entre nossa prática cotidiana e as aspirações sociais e educativas de um ensino guiado pelos valores da igualdade, justiça e democracia.

Por essa razão, a formação docente deve desvelar a finalidade da educação, permitindo ao profissional que se compõe, perceber-se como sujeito responsável por uma prática social encarregada de transformar o ensino, na condição de acesso à igualdade de direitos e justiça, em meio a um contexto de relações de diálogo e participação.

Com Freire (1987, p.33) acreditamos que "só existe saber na invenção, na reinvenção, na busca inquieta, impaciente, permanente, que os homens fazem no mundo, com o mundo e com os outros. Busca esperançosa também”.

\section{Metodologia}

O desenvolvimento do projeto ocorre por meio da pesquisa-ação, que permite um movimento de conhecer e agir, desta forma foram promovidos encontros pedagógicos na escola, com vistas a qualificar as reuniões pedagógicas, inserindo a pesquisa como principal instrumento de protagonismo dos professores, no intuito de que estes possam coletivamente construir conhecimentos que sirvam para tratar as problemáticas que surgem no cotidiano escolar e melhorar suas condições de trabalho. As reuniões pedagógicas da escola que ocorrem quinzenalmente, serviram de lócus privilegiado para a efetivação do projeto, devido a sua relevância e institucionalidade.

[...] a jornada de trabalho dos docentes poderá ser de até 40 (quarenta) Hora e incluirá uma parte de Hora de aula e outra de Hora de atividades, estas últimas correspondendo a um percentual entre $20 \%$ (vinte por cento) e $25 \%$ (vinte e cinco por cento) do total da jornada, consideradas como Hora de atividades aquelas destinadas à preparação e avaliação do trabalho didático, à colaboração com a administração da escola, às reuniões pedagógicas, à articulação com a comunidade e ao aperfeiçoamento profissional, de acordo com a proposta pedagógica de cada escola (BRASIL/CNE,1997, p.2). 
Foram utilizadas cinco reuniões para a intervenção acontecer e tornar possível de observação uma fatia próxima ao movimento real, capaz de produzir resultados possíveis de serem analisados, o acompanhamento e registro das vivências foram realizados através de diário de campo e questionários aplicados ao termino de cada momento. Os sujeitos participantes da pesquisa foram nove professores que lecionam nos anos finais do ensino fundamental e a coordenadora pedagógica da instituição. As reuniões constituíram espaço formativo a partir da pesquisa e propiciaram aos docentes a possibilidade de discutir, refletir e elaborar estratégias ou ainda reformular conceitos que estruturam seu fazer pedagógico. Exatamente como afirma Pinto:

Ao se constituírem como espaços coletivos de reflexão sobre o fazer docente, de trocas de experiências, de aprofundamento teórico, de busca de superação das dificuldades e de construção de conhecimentos, as reuniões pedagógicas se estabelecem como espaços efetivos para a formação continuada dos professores e educadores (2010, não paginado).

A primeira reunião articulada ao projeto de pesquisa ocorreu com o objetivo de apresentar aos docentes uma nova perspectiva para esse espaço, explicitando o sentido pleno da reunião pedagógica, bem como evidenciando seu caráter formativo, a segunda reunião partiu da análise coletiva dos dados tabulados a partir de um questionário, previamente respondido pelos professores, que permitiu serem elencados os conflitos que se apresentam com mais frequência e prejudicam o desenvolvimento da docência em sala de aula. A partir desses dados, os professores foram questionados pela pesquisadora de que forma seria possível qualificar o espaço da reunião pedagógica para tratar das problemáticas que afligem o trabalho destes. Os docentes sugeriram que organizados em grupos tratassem de cada situação considerada problema, então formaram trios para nas próximas reuniões apresentarem suas pesquisas.

Deste modo, as três reuniões seguintes foram geridas pelos grupos de professores, os quais trouxeram para compartilhar com os colegas artigos que julgaram serem capazes de embasar discussões e reflexões acerca da prática docente, promovendo a formação a partir do contexto no qual estão inseridos, buscando melhorar suas condições de trabalho a partir de um aporte teórico.

\section{Discussão e resultados}

Na última década, são perceptíveis os investimentos do governo federal acerca da formação de professores, por entenderem que por meio da qualificação da mão de obra destes, 
o resultado de seu trabalho será mais produtivo, atingindo níveis de ensino mais elevados. A questão é que enquanto aos docentes não for permitido ocupar o seu lugar na sociedade de pensar a educação, e o exercício de sua formação não estiver pautado na autonomia dos sujeitos que o fazem, dificilmente se desencadeará uma atuação no âmbito educacional, que transforme a realidade como está posto em Kuenzer (2003, p. 24):

O trabalho teórico, que por sua vez não prescinde da prática, é que determinará a diferença entre prática enquanto repetição reiterada de ações que deixam tudo como está e práxis enquanto processo resultante do contínuo movimento entre teoria e prática, entre pensamento e ação, entre velho e novo, entre sujeito e objeto, entre razão e emoção, entre homem e humanidade, que produz conhecimento, e por isto revoluciona o que está dado, transformando a realidade

Para uma evolução no campo da formação de professores, é urgente a superação do caráter técnico, este excedido pela criticidade, reflexão e mediação, renovando conceitos e fortalecendo o movimento da autonomia, atentando-se para o profissional que se constitui nesse processo e não para a quantidade no propósito de atingir metas e sanar problemas de ordem estrutural.

Freire elucida que "na formação permanente dos professores, o momento fundamental é o da reflexão crítica sobre a prática. É pensando criticamente a prática de hoje ou de ontem que se pode melhorar a próxima prática (FREIRE, 1996, p.44). Com o propósito de pensar criticamente a prática no espaço das reuniões pedagógicas, o projeto desencadeou resultados positivos, os registros nos diários de campo de cada professor e da pesquisadora, os questionários e as vivências de cada momento, evidenciam dados que permitem essa constatação.

Durante os encontros, os docentes ao compartilhar os materiais trazidos por eles, como artigos, reportagens, capítulos de livros, entre outros, despertavam nos colegas e em si mesmos a vontade de se revigorar por meio das teorias ou relatos de experiências pesquisados e ali trazidos. Os embates, as discussões faziam com que surgissem comparações, indagações e o entusiasmo de repensar o próprio fazer pedagógico e também sentir-se capacitado para gerenciar junto aos alunos os conflitos que surgem na sala de aula. A fala de uma professora afirma esse dado.

$\mathrm{O}$ artigo que o colega trouxe pra compartilhar me auxiliou muito a entender as razões pelas quais existe tanto descompromisso da família, e como isso repercute no comportamento em sala de aula, e me estimulou a pensar estratégias ou projetos para tratar dessa questão que me afeta. 
A coordenadora pedagógica da escola, também demonstra sua compreensão em relação a espaços pertinentes à formação como é o da reunião pedagógica, assim como o entendimento de sua importância. Ao responder um questionário faz o seguinte registro:

Momentos de discussão e reflexão como este devem ser permanentes, as reuniões pedagógicas não podem servir apenas para recados ou atividades burocráticas como conselho de classe, depois dessa oportunidade que este projeto nos deu, jamais tratarei o espaço das reuniões pedagógicas sem pensar em sua função formativa.

Os dados colhidos e analisados comprovam a relevância do projeto, bem como o alcance de seu objetivo, e ainda destacam a mudança de paradigma que se efetuou, o que se percebe pertinente no registro realizado no diário de campo de outra professora.

Gostaria que depois que terminasse o projeto pudéssemos continuar tendo esses momentos de formação na escola e a partir dos problemas que são nossos. Na maioria dos cursos de formação continuada que participo, não encontro uma aproximação com a realidade em que trabalho e muito pouco aproveito para a minha prática.

O projeto evidenciou que é possível consolidar no espaço escolar uma formação continuada capaz de resgatar a autonomia docente, através do diálogo, da participação, da reflexão e da pesquisa, pode-se coletivamente contribuir para a melhoria das condições de trabalho nas escolas.

\section{Considerações finais}

Um novo olhar para o espaço das reuniões pedagógicas trouxe novas possibilidades de formação docente para os professores de uma escola pública municipal. A dinâmica do trabalho educativo aflora uma demanda de gerenciamento dos conflitos que emergem da relação professor e aluno na sala de aula. As reuniões pedagógicas como espaço formativo, que trata das questões concretas que se apresentam no contexto onde se realiza a docência, reaproximou os professores da pesquisa, da busca pelo conhecimento, pela teoria e permitiu uma análise crítica da prática, contribuindo para o protagonismo docente nas tomadas de decisões ou na elaboração de questões que dizem respeito ao seu trabalho.

Torna-se relevante destacar que alguns fatores interferem negativamente para que as reuniões pedagógicas desempenhem seu papel formativo. A carga horária dos professores, as demandas de calendário e cumprimento de prazos, a organização dos relatórios de notas, 
presenças e faltas, entre outros elementos que invadem as reuniões pedagógicas e absorvem grande parte do seu tempo no cumprimento de questões burocráticas, assim como a realização de combinados e avisos que devido a correria diária acabam por encontrar pertinência nesse momento de encontro coletivo.

Contudo, é imprescindível que se atente para o âmbito formativo da reunião de professores e para tal, o coordenador possui um papel fundamental, que é de planejar, estruturar e viabilizar este momento dentro da escola, sem descaracterizá-lo. A escola, através de sua gestão precisa compreender a importância e a necessidade de um ambiente que dê voz aos professores, que solidifique a autonomia e a busca pelo conhecimento, em detrimento da garantia de uma formação docente capaz de contribuir para a melhoria das condições do trabalho docente, portanto deve respeitar e garantir este espaço.

\section{Referências}

ABDALlA, M. F. B. Políticas de formação de professores: desafios e perspectivas. Collatio 11 abr-jun 2012 CEMOrOc-Feusp / IJI - Univ. do Porto. Disponível em: <http://www.hottopos.com/collat11/23-32FatAbd.pdf>. Acesso em: 26 dez 2017.

BRASIL. Decreto N. ${ }^{\circ}$ 2.494, de 10 de fevereiro de 1998. Regulamenta o Art. 80 da LDB (Lei n. ${ }^{\circ}$ 9.394/96). Brasília: $1998 . \quad$ Disponível em: <http://portal.mec.gov.br/seed/arquivos/pdf/tvescola/leis/D2494.pdf>. Acesso em: $19 \mathrm{dez}$ 2017.

. Lei LDB nº 9.394, de 20 de dezembro de 1996. Brasília: DF, 1996.

BRASIL. Lei 11.738 de 16 de julho de 2008. Regulamenta a alínea "e" do inciso III do caput do art. 60 do Ato das Disposições Constitucionais Transitórias, para instituir o piso salarial profissional nacional para os profissionais do magistério público da educação básica. Disponível em: 〈http://www.planalto.gov.br/ccivil_03/_ato2007-2010/2008/lei/111738.htm>. Acesso em: 02 mar. 2018.

CARVALHO, Ademar de Lima. Os caminhos perversos da educação: a luta pela apropriação do conhecimento no cotidiano da sala de aula. Cuiabá. Edufmt.2005.

CELANI, M. A. A. A educação continuada do professor. SBPC Ciência e Cultura, São Paulo, v. 40, n. 2, p. 158-163, fev. 1998.

CONTRERAS, José. A autonomia de professores. São Paulo: Cortez, 2002. 
GIOLO, Jaime. A educação a distância e a formação de professores. Educ. Soc., Campinas, vol. 29, n. 105, p. 1211-1234, set./dez. 2008. Disponível em: <http://www.scielo.br/pdf/es/v29n105/v29n105a13>. Acesso em: 19 dez 2017.

FREIRE, Paulo. Pedagogia do oprimido. 17.ed. Rio de Janeiro: Paz e Terra, 1987. Pedagogia da autonomia: saberes necessários à prática educativa. 25. ed. São Paulo: Paz e Terra, 1996. (Coleção leitura). Pedagogia da Indignação. Cartas e outros escritos. São Paulo: UNESP, 2000. Pedagogia do oprimido. Rio de Janeiro: Paz e Terra, 2005.

IMBERNÓN, F. Formação continuada de professores. Porto Alegre: Artmed, 2010.

KUENZER, Acácia Z. Competência como Práxis: Os Dilemas da Relação entre Teoria e Prática na Educação dos Trabalhadores. Boletim Técnico do SENAC, Rio de Janeiro, Vol. 29, n'1. jan/abr., 2003.

MARCELO, C. Formação de professores: para uma mudança educativa. Porto: Porto Editora, 2013.

NÓVOA, A. (Coord.). Os professores e a sua formação. Lisboa: Publicações Dom Quixote, 1995.

PIMENTA, Selma Garrido. Saberes pedagógicos e atividade docente. São Paulo: Cortez 1999.

PINTO, M.F.N. Reuniões pedagógicas. In: OLIVEIRA, D.A.; DUARTE, A.M.C.; VIEIRA, L.M.F. DICIONÁRIO: trabalho, profissão e condição docente. Belo Horizonte: UFMG/Faculdade de Educação, 2010.

TARDIF, Maurice. Saberes profissionais dos professores e conhecimentos universitários. Revista Brasileira de Educação. Jan/fev/mar/abr. 2000, n. 13, p. 20. 